\title{
Use of the Generating Options for Active Risk Control (GO-ARC) Technique Can Lead to More Robust Risk Control Options
}

\author{
Authors \\ Alan J. Card, PhD, MPH ${ }^{1}$, Mecit Can Emre Simsekler, MSc ${ }^{2}$, Michael Clark, PhD ${ }^{3}$, James R. Ward, \\ $\mathrm{PhD}^{2}$, P. John Clarkson, $\mathrm{PhD}^{2}$
${ }^{1}$ Evidence-Based Health Solutions, LLC $\quad{ }^{2}$ Engineering Design Centre
Corresponding author Department of Engineering
University of Cambridge
Cambridge, UK \\ Notre Dame, IN
${ }^{3}$ Center for Social Research
University of Notre Dame
Notre Dame, IN \\ Email: alan.j.card@gmail.com \\ This is a pre-print draft of a paper that has been accepted for publication in the International Journal of Risk \& Safety in \\ Medicine. The final and definitive version will be published at: http://www.iospress.nl/journal/the-international-journal-of-risk- \\ safety-in-medicine/ \\ Please cite this paper as: \\ Card AJ, Simsekler MCE, Clark M, Ward JR, Clarkson PJ. Use of the Generating Options for Active Risk Control (GO-ARC) \\ Technique Can Lead to More Robust Risk Control Options. Int J Risk Saf Med. [In press]
}

\begin{abstract}
Background: Risk assessment is widely used to improve patient safety, but healthcare workers are not trained to design robust solutions to the risks they uncover. This leads to an overreliance on the weakest category of risk control recommendations: administrative controls. Increasing the proportion of non-administrative risk control options (NARCOs) generated would enable (though not ensure) the adoption of more robust solutions.
\end{abstract}

Objectives: Experimentally assess a method for generating stronger risk controls: The Generating Options for Active Risk Control (GO-ARC) Technique.

Methods: Participants generated risk control options in response to two patient safety scenarios. Scenario 1 (baseline): All participants used current practice (unstructured brainstorming). Scenario 2: Control group used current practice; intervention group used the GO-ARC Technique. To control for individual differences between participants, analysis focused on the change in the proportion of NARCOs for each group.

Results: Control group: Proportion of NARCOs decreased from 0.18 at baseline to 0.12 . Intervention group: Proportion increased from 0.10 at baseline to 0.29 using the GO-ARC Technique. Results were statistically significant. There was no decrease in the number of administrative controls generated by the intervention group.

Conclusion: The Generating Options for Active Risk Control (GO-ARC) Technique appears to lead to more robust risk control options. 


\section{INTRODUCTION}

Healthcare organizations in many countries have adopted operational risk management tools such as root cause analysis (RCA),[1-5] failure mode and effects analysis (FMEA),[6-8] and -to a lesser extent- other such techniques[8-12] to address the systems-level determinants of patient safety. One key feature of these approaches is that they are exclusively focused on problem exploration (risk assessment). They provide no direct support for the process of translating this problem-focused learning into solutions-focused interventions (risk control).[2,9,13,14]

The unexamined assumption behind this state of affairs is that successful risk assessment will necessarily lead to successful risk control. This approach may be successful in the industrial settings where these techniques were developed (the chemical process industry, for instance[15]), but recent evidence suggests that this success does not extend to the fields of healthcare[2] or occupational health and safety.[16] This may reflect that fact that the tools of operational risk assessment were created both by and for engineers, who are specifically trained to develop high-quality, robust solutions in response to identified requirements.[17] Healthcare workers are not trained in these skills,[18] nor are they supported by risk management policies and procedures that provide adequate support for this function.[14] As a result, they face significant challenges in generating (and recognizing) high-quality risk controls.[2,19,20]

The strength of risk controls can be assessed using the three-tiered hierarchy of risk control.[2] The most effective and robust (i.e., prone to continue working over time) category is Elimination of the Hazard or the Target. The intermediate level is made up of Design Controls (aka Engineering Controls[16]), interventions like physical barriers, forcing functions, equipment or 
location changes, etc., that do not rely on people to do the right thing. The weakest category is made up of Administrative Controls, which do rely on people to do the right thing (e.g., training, policies and procedures, and alarms). Current practice relies overwhelmingly on this least robust category.

James Bagian, a pioneer in the application of operational risk assessment techniques to healthcare, has demonstrated the fallibility of administrative controls. In an analysis of Joint Commission survey data comparing different types of risk controls under both announced and unannounced inspections, he found that there was essentially no difference in compliance rates for "engineering changes" (i.e., design controls) between announced and unannounced inspections. But compliance rates for administrative controls were much lower during unannounced inspections vs. announced inspections.[18] In short, design controls work regardless of whether anyone is watching, while administrative controls may require constant monitoring in order to be reliable.

Among published RCAs in healthcare, administrative controls account for $\sim 80 \%$ of all risk controls recommended or implemented. In the sub-set of studies describing which risk controls has been implemented, 50\% resulted exclusively in administrative controls.[2] This may be part of the reason why the adoption of RCA, FMEA and other methods has not led to systemic improvement in the rate of patient harm.[21] Very similar findings have also been shown in a recent analysis of occupational health and safety incident investigations.[16]

The Generating Options for Active Risk Control (GO-ARC) Technique has been developed as one step toward addressing this problem. It is a structured brainstorming method designed to 
increase the proportion of non-administrative risk control options considered after a risk assessment. The GO-ARC Technique was developed for use as part of the broader Active Risk Control (ARC) Toolkit,[22,23] which includes additional tools for assessing the risk control options that result.

The technique could also be used on a stand-alone basis, or in combination with other approaches to assessing and selecting risk control options -e.g., the Commercial Aviation Safety Team-based approach[19] or the Lovebug Diagram[24]. Unlike the ARC Toolkit, neither of these alternate approaches currently includes a component for generating high-quality risk control options in the first place.

Previous literature on the GO-ARC Technique has been limited to one uncontrolled before-andafter study.[25] This article presents the first experimental assessment of the method, and one of very few experimental studies of healthcare risk management techniques in general.

\section{METHODS}

\subsection{Hypothesis}

The GO-ARC Technique improves the proportion of non-administrative risk controls generated versus current practice.

\subsection{Recruitment}

Participants were recruited through the listserv of the American Society for Healthcare Risk Management (ASHRM), relevant LinkedIn groups (e.g., those associated with the National Association for Healthcare Quality and the Institute for Health Improvement), and Academia.edu. The posts requested participation from those involved in healthcare risk 
management / patient safety, and healthcare workers who might be called upon to participate in a root cause analysis. No personally identifying information was collected.

\subsection{Procedure}

The study was conducted using the Qualtrics online survey tool. In step one, Qualtrics randomly assigned participants to either the control group or the intervention group. Then both groups were asked to generate solutions to the same patient safety scenario (Scenario 1) using current practice, i.e., unstructured brainstorming;[26,27] participants were asked to "Please brainstorm risk control options (potential risk control action plans) to address the patient safety risk described in Scenario 1, below." This provided the baseline data required to assess improvement.

Participants then generated solutions in response to a second scenario (Scenario 2), which was also the same for both groups. The control group again used current practice. The intervention group received a brief description of the GO-ARC Technique and the hierarchy of risk controls, then used the GO-ARC Technique to generate risk control options. No time limits were imposed. Responses were entered as free text and coded according to the 3-tiered hierarchy of risk controls.

To control for individual differences between participants, the analysis focused on the change in the proportion of non-administrative risk controls for each group between Scenario 2 and baseline (Scenario 1). See Figure 1 for a diagram illustrating the flow of subjects through the experiment. 


\subsection{Statistical tests}

Statistical analysis focused on the proportion of non-administrative risk control options generated, specifically the change in the difference between control and intervention groups from Scenario 1 to Scenario 2. Given the nature of the responses, a binomial regression model examining the number of non-administrative responses out of the total number of responses was employed with a standard logit link function. In addition, a random effect for subject was included as part of the model. This generalized linear model was conducted primarily using the glmer function in the R package lme4.[28]

\subsection{The GO-ARC prompts}

Participants randomized into the experimental condition were asked to use a series of five brainstorming prompts to generate risk control options in response to the adverse incident scenarios. (See Table 1) Each prompt is a risk control strategy. The first three consist of the 3tiered hierarchy of risk controls. The remaining two, detection/situational awareness and preparedness help users consider risk controls to reduce the severity of harm or prevent harm in the midst of an on-going systems breakdown; they are aimed at promoting resilience[29-31], as opposed to focusing solely on preventing systems breakdowns in the first place. This twopronged approach is based on the model, widely accepted in the risk management community, of risk as the product of likelihood and consequences.[32] 
Table 1. The GO-ARC Prompts

\begin{tabular}{ll} 
Prompt & Definition \\
\hline Elimination & Eliminate the hazard or the target from the \\
& system. This can mean transferring the risk to \\
& another entity, substituting a less hazardous \\
& process, material, etc., or discontinuing the \\
& hazardous process entirely.
\end{tabular}

Design controls With a focus on physical barriers, isolation, forcing functions, human factors, and failsafe design, design controls improve safety without relying on people to do the right thing.
Administrative Policies, procedures, training and other controls controls that depend on people taking the correct actions.

Detection/ These risk controls focus on knowing that situational something is going wrong, or is likely to do so, awareness in time to prevent it, or reduce its impact.

Preparedness Preparedness is the state of being ready for predictable risks. Risk controls in this category involve having a response ready to go if the risk occurs. It means more than having a plan: It also means having the resources available and ready to be used to implement that plan.

During the structured brainstorming process, the prompts were displayed along with their definitions (see Table 1) and illustrative examples.

\subsection{Patient safety scenarios}

The two patient safety scenarios were presented in the form of "5 Whys" analyses, [33] as shown in Boxes 1 and 2 below. The first was a fatal medication error, and the second an inpatient suicide. The 5 Whys approach was chosen not because it is a particularly powerful risk assessment technique, but because A) It would be familiar to most healthcare workers who have 
received any RCA training; B) It allows for a very concise description of the scenario; and C) Its chronological approach closely mirrors real-world practice in healthcare RCA, which tends to focus on the timeline of a 'series of unfortunate events,' rather than the underlying systems issues that gave rise to those events.[34]

\section{Box 1. Scenario 1}

\section{Scenario 1}

\section{Risk: Patient dies of drug overdose}

1. Why: Patient received twice the intended dose of a highly-toxic medication by IV

2. Why: Medication accidentally added to IV twice

3. Why: Nurse was interrupted three times by fellow clinicians with requests for information while trying to prepare drugs

4. Why: Nurse to patient ratio was unusually low

5. Why: Many nurses were out with the flu

6. Why: Low influenza vaccination rate among healthcare workers at the facility

\section{Box 2. Scenario 2}

\section{Scenario 2}

\section{Risk: Patient suicide}

1. Why: Patient hung himself from pipes beneath the sink of a public restroom near the dialysis unit

2. Why: Patient absconded from psychiatric unit

3. Why: Patient walked out the door of the psychiatric unit right behind a patient transportation clerk who was exiting the unit. The patient transportation clerk noticed that the patient was leaving; she assumed he was allowed to, because no one from the unit told the patient to stop.

4. Why: The patient care assistant at the front desk saw the patient leaving, but assumed the patient was going with the patient transportation clerk to attend an appointment elsewhere in the hospital

5. Why: Poor communication between the patient transportation clerk and the patient care assistant, both of whom thought the other was responsible for the patient. 


\subsection{Coding responses}

Responses were independently coded by two members of the research team using the three-tiered hierarchy of risk controls, and disagreements between the two were resolved by consensus. A third member of the research team was available to adjudicate any disagreements that could not be resolved by consensus. A brief description of each category can be found in Table 1; illustrative examples drawn from participant responses are shown in Box 3 below.

Box 3. Example responses

\section{Eliminate the hazard or target (Elimination)}

Examples from participant responses:

Scenario 1: "All IV admixtures should be compounded/mixed by the pharmacy staff" [Transferring the risk to another entity]

Scenario 2: "Eliminate psychiatric services from the facility" [Not delivering the hazardous service]

\section{Design Controls}

Examples from participant responses:

Scenario 1: "Ensure pharmacy cannot fill order twice; block in system for categories of drugs." [Forcing function]

Scenario 2: "Design a "holding area" that would cause a patient to get through 2 sets of locked doors to get off of the unit." [Physical barrier]

Administrative Controls

Examples from participant responses:

Scenario 1: "Highly toxic medications should have 'another set of eyes' before administration, e.g 2 nurses review orders, medications, label, documentation." [Procedure - double-checking]

Scenario 2: “Train all staff to ask patient who they are and why they are leaving. " [Training]

\section{Not a Risk Control or Repeated Risk Controls}

Responses that would not directly lead to risk reduction (e.g., general comments, suggestions for further risk assessment, etc.) were ignored, as were repeated suggestions of the same risk control by a single participant (e.g., proposing a door alarm in response to the design controls prompt and again in response to the detection / situational awareness prompt). 


\section{RESULTS}

\subsection{Responses}

Seventy-five participants completed the survey; 65 provided usable responses. Forty-one were randomized to the control group, and 24 to the intervention group. The remaining 10 were excluded. Five were excluded because the participants misunderstood the nature of the exercise and responded exclusively by identifying risks or with suggestions for further risk assessment. Three were excluded because they provided nonsense responses $(n=3)$. One participant did not feel competent to respond to Scenario 2 due to a lack of familiarity with psychiatric units, and one continued responding to Scenario 1 during the Scenario 2 portion of the exercise.

The nonsense responses (e.g., responding "q" to every question) were limited to the GO-ARC Technique, which may indicate that these were examples of previous respondents returning to review the method. Because no personally identifying information was collected (e.g., IP addresses), however, this cannot be confirmed. A similar number of responses were excluded from both groups $(5 \pm 2)$. One participant who was included in the analysis gave a mix of usable and unusable responses to Scenario 1, but gave only unusable responses to Scenario 2. Figure 1 illustrates the flow of participants through the experiment. 


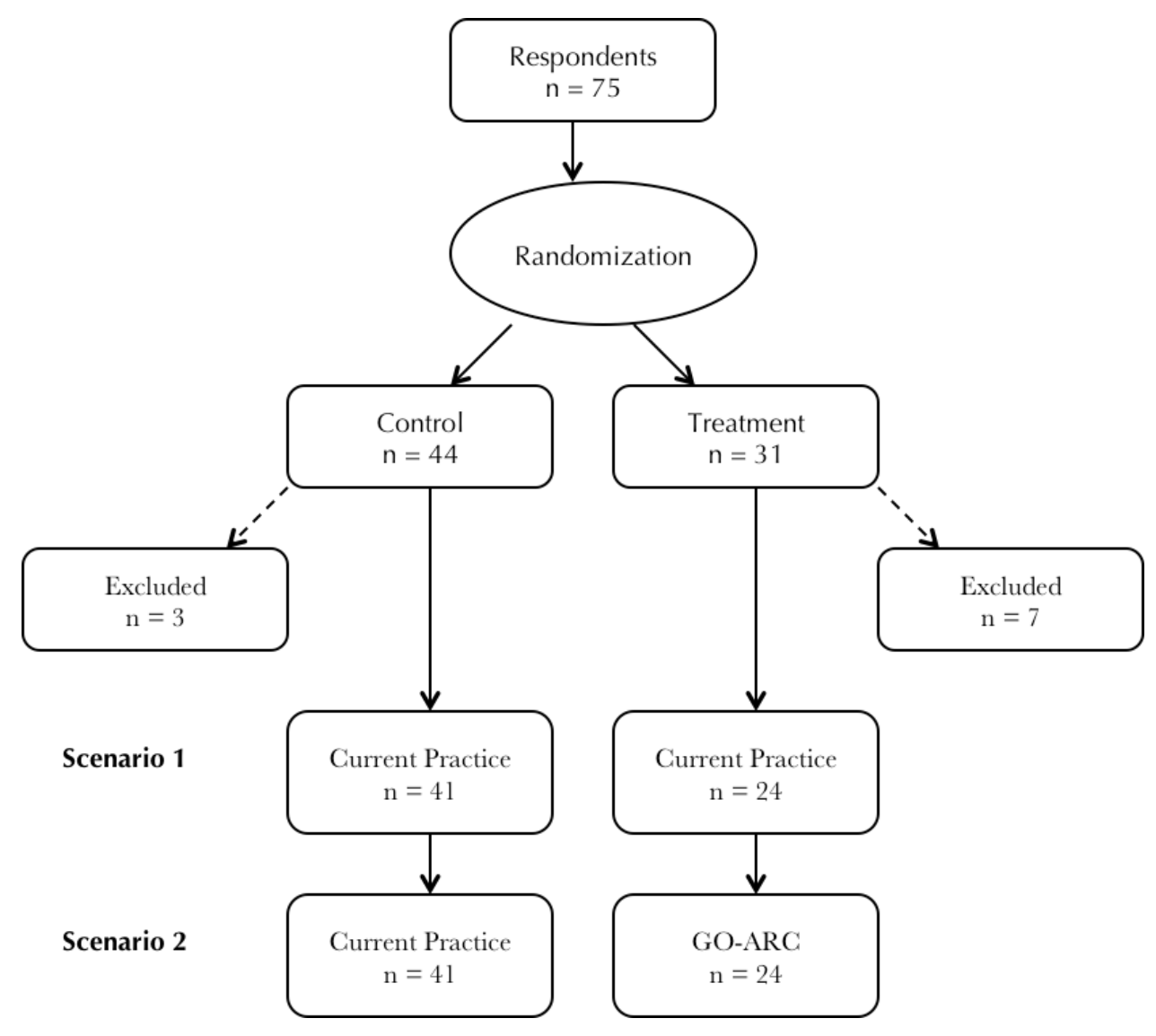

\subsection{Outcomes}

\subsubsection{Descriptive statistics}

Use of the GO-ARC Technique was associated with the generation of a higher proportion of non-administrative risk control options. This was not the result of a reduction in the number of administrative risk control options generated using the technique. In fact, use of the GO-ARC Technique was associated with the generation of a higher number of risk control options in all three categories (elimination, design controls, and administrative controls). 
As shown in Table 2, the number and distribution of risk controls at Scenario 1 were very similar between the intervention group and the control group. At Scenario 2, the proportion of nonadministrative risk controls generated by the control group dropped slightly as did the overall number of risk control options generated. In contrast, use of the GO-ARC Technique by the intervention group in Scenario 2 was associated with an increase in the counts for all three risk control categories, as well as a marked increase in the proportion of non-administrative risk controls generated (approximately 3 times higher than baseline).

Table 2. Mean/median number of risk control options generated and proportion of non-administrative controls: category by scenario / treatment group

\begin{tabular}{llllll} 
& & \multicolumn{2}{c}{ Scenario 1 } & \multicolumn{2}{c}{ Scenario 2 } \\
Group & Risk control category & Mean & Median & Mean & Median \\
\hline Control & Elimination & 0.39 & 0 & 0.07 & 0 \\
& Design & 0.22 & 0 & 0.46 & 0 \\
& Administrative & 3.71 & 4 & 3.44 & 3 \\
Intervention & Elimination & 0.17 & 0 & 1.04 & 1 \\
& Design & 0.25 & 0 & 2.08 & 2 \\
& Administrative & 3.71 & 3 & 7.42 & 7 \\
\hline Control & Prop. non-admin controls & 0.18 & 0.14 & 0.12 & 0 \\
Intervention & Prop. non-admin controls & 0.10 & 0 & 0.29 & 0.29 \\
\hline
\end{tabular}

\subsubsection{Analysis}

Overall results from the generalized linear mixed model suggest an adequate fit to the data $\left(X_{3}^{2}=28.92, p<.001\right)$. Table 3 displays the fixed effects; there was no significant variation among individuals. The statistically significant interaction might suggest that the treatment group difference of experimental versus control increases at scenario two compared to scenario 
one, but interaction effects in these models can be somewhat difficult to interpret (see, for example, references [35-37]).

Table 3. Fixed effects from the statistical model

\begin{tabular}{llllll}
\hline & Raw & Standard & $\mathrm{z}$ value & $\operatorname{Pr}(>|\mathrm{z}|)$ & Odds Ratio \\
& Coefficient & Error & & & \\
Intercept & -1.81 & 0.22 & -8.36 & $<0.01$ & 0.16 \\
Group & -0.38 & 0.40 & -0.96 & 0.34 & 0.68 \\
Scenario & -0.05 & 0.31 & -0.17 & 0.87 & 0.95 \\
Group by scenario & 1.37 & 0.48 & 2.87 & $<0.01$ & 3.94 \\
\hline *Reference group for group is the control group; reference group for scenario is Scenario 1
\end{tabular}

Attention is focused instead on the expected values for each cell, which provides more clearly interpretable results. These are provided in Table 4. Again, there appears to be no difference between treatment groups for scenario one, followed by a noticeable increase in proportion of non-administrative responses among the intervention group at scenario two.

Table 4. Expected values for proportion of non-administrative options generated by treatment group and scenario

\begin{tabular}{lll}
\hline & Scenario 1 & Scenario 2 \\
Control & 0.14 & 0.13 \\
Experimental & 0.10 & 0.30 \\
\hline
\end{tabular}

These increases did not appear to be the result of learning effects, as evidenced by the lack of any significant difference in control group responses between the two scenarios. Additionally, as shown in Table 2, the increase in the proportion of non-administrative controls was accomplished without a corresponding decrease in the number of administrative controls 
generated; indeed, the number of administrative controls was also higher using the GO-ARC Technique.

\section{DISCUSSION}

If healthcare risk management approaches are to live up to their promise of improving patient safety, they will have to result not only in a better understanding of patient safety problems, but also in better solutions. This study provides the first experimental evidence to support the transition from current practice, which focuses almost exclusively on risk assessment, toward a more balanced approach to risk management.[38] It also addresses a critical lack of evidence to guide risk management practice more generally.[39]

The findings of this study lend weight to previous work on the GO-ARC Technique. A beforeand-after study using the Technique suggested that it may increase the quantity, quality, variety, and novelty of risk controls generated in response to a patient safety incident.[25] Use of the GO-ARC Technique in a real-world case study of the broader ARC Toolkit resulted in the generation of 12 risk control options for reducing pressure ulcers in a hospital setting. Seven of these (58\%) were non-administrative risk controls. The resulting action plan included all seven non-administrative control options, along with four of the five administrative controls.[23] The experimental study presented here is a significant step forward for the evidence base on the use of this method, and strongly suggests that current practice can be improved upon..

It is important to note that generating better risk control options is a necessary, but not sufficient, step toward implementing and sustaining better risk controls in practice. In current practice, risk 
control implementation rates appear to vary inversely with risk control quality; that is, implementation rates are highest for administrative controls and lowest for elimination.[2] Thus, the impact of the GO-ARC Technique may be highest when it is paired with tools to assist in selecting, implementing, and sustaining the best available options. These might include the Active Risk Control (ARC) Toolkit (of which the GO-ARC Technique is one component),[22][23] the Lovebug Diagram,[24] or other approaches of similar scope.[19]

A user acceptance study of the broader Active Risk Control (ARC) Toolkit, which includes the GO-ARC Technique, found that users perceived the Toolkit as useful, valuable, and reasonably easy to use. They felt that the Toolkit improved the quality of the risk control process and led to increased confidence in the recommendations they produced. The cost (free) was felt to be acceptable, and most respondents said that they would use the Toolkit again in the same or similar circumstances.[22] The GO-ARC Technique and the broader ARC Toolkit are both available for free at www.activeriskcontrol.com.

\subsection{Limitations}

Although this study presents the highest quality evidence to date on the GO-ARC Technique, it is not without limitations. Most importantly, the head-to-head comparison with current practice examined only one patient safety scenario. Because the level of improvement is certain to vary based on the scenario in question, the exact degree of improvement demonstrated cannot be generalized from a single comparison. Additional research will be required to determine the range of improvement that can be expected using the technique. 
In terms of raw counts, there could also be some differences resulting from unmeasured attributes of the participants (e.g., profession, years of experience, etc.) which, given the relatively small number participants in this study $(n=65)$, and especially in the intervention group ( $\mathrm{n}=24$ ), might not have been fully cancelled out through randomization. However, the study design's focus on improvement between Scenario 1 and Scenario 2 controls for any such variation in the analysis we present. Further, with regard to the importance of experience, the earlier pilot study on the GO-ARC Technique [25] suggests that this tool can lead to significant improvement even when used by highly-experienced healthcare risk managers.

Similarly, it is possible that the individual nature of the experimental task might have influenced the results in some way. Risk control options generation in healthcare is often, though not always, a small group activity. However, the before-and-after pilot study was conducted in a group setting and it achieved very similar results to the experimental study reported here.

Finally, it may be worth reiterating that generating a better pool of risk control options does not guarantee that higher quality risk controls will actually be implemented or sustained in practice. Not all 'strong' risk control options will prove feasible or appropriate,[40] and even when they are, it is possible that higher-quality risk control options will be ignored in favor of traditional, non-robust approaches like training[41,42]_and policy development.[43,44] The GO-ARC Technique is likely to be most effective when paired with a systematic approach to analysing and evaluating risk control options, as well as managing change. 


\subsection{Balancing the Evidence}

Despite the limitations above, this study represents a significant step forward for evidence-based practice in generating options for risk control. Not only is current practice not actively supported by the evidence, but a systematic review of risk control after root cause analysis has shown that current practice in healthcare consistently results in poor quality risk control options.[2] Thus, while the evidence for the GO-ARC method is limited at this stage, it compares very favorably to the (non-existent) evidence in favour of current practice. This inadequate basis for current practice highlights the pressing need for evidence-based approaches to patient safety and healthcare risk management.[39,45-47]

Given the very small time investment required, and the fact that this technique does not appear to reduce the number of administrative risk controls generated (i.e., it does not limit the choices available to users), the results of this study may be a sufficient basis for recommending the use of the GO-ARC Technique in practice.

\subsection{Applicability Beyond the Healthcare Domain}

The GO-ARC Technique has been developed specifically to address identified needs in healthcare risk management and patient safety improvement, and has not yet been tested in any other field. Additional research will be required to determine whether it can improve upon current practice in other risk management domains. The approach is entirely generic, however, so there is no obvious reason why it should not be more broadly applicable.

Because current risk control practice in occupational health and safety appears similar to that in healthcare,[16] extending this work to encompass workplace safety would seem the logical next 
step. It may also prove valuable in other areas in which risk assessments are conducted by those with deep domain expertise, but with limited training in engineering, ergonomics,[48] or other design-oriented disciplines (e.g., police involved in a terrorism risk assessment, school administrators planning for a communicable disease outbreak, etc.).

\section{CONCLUSION}

The Generating Options for Active Risk Control (GO-ARC) Technique appears to improve the quality of risk control options generated in response to a patient safety incident scenario. In so doing, it may enable healthcare workers involved in risk management to make better decisions about how to improve patient safety. Additional research is warranted, to determine both the degree of improvement that can be expected across different patient safety scenarios, and the degree to which the technique might prove useful in other risk management domains.

\section{REFERENCES}

1. Bagian JP, Lee C, Gosbee J, DeRosier J, Stalhandske E, Eldridge N, Williams R, Burkhardt M. Developing and deploying a patient safety program in a large health care delivery system: you can't fix what you don't know about. Jt Comm J Qual Improv. 2001;27(10):522-32.

2. Card AJ, Ward J, Clarkson PJ. Successful risk assessment may not always lead to successful risk control: A systematic literature review of risk control after root cause analysis. J Healthc Risk Manag. 2012;31(3):6-12.

3. National Patient Safety Agency. Root cause analysis (RCA) tookit [Internet]. 2004 [cited 2014 Jun 7]. Available from: http://www.nrls.npsa.nhs.uk/resources/collections/rootcause-analysis/?entryid $45=59901$

4. Taitz J, Genn K, Brooks V, Ross D, Ryan K, Shumack B, Burrell T, Kennedy P. Systemwide learning from root cause analysis: a report from the New South Wales Root Cause Analysis Review Committee. Qual Saf Healthc. 2010 Jul;19(6):e63. 
5. Canadian Patient Safety Institute. Canadian Incident Analysis Framework [Internet]. Edmonton, AB; 2012. Available from:

http://www.patientsafetyinstitute.ca/English/toolsResources/IncidentAnalysis/Pages/defau lt.aspx

6. DeRosier J, Stalhandske E, Bagian JP, Nudell T. Using health care failure mode and effect analysis: The VA National Center for Patient Safety's prospective risk analysis system. Jt Comm J Qual Improv. 2002;28(5):248-67.

7. Dhillon BS. Methods for performing human reliability and error analysis in health care. Int J Health Care Qual Assur. 2003;16(6):306-17.

8. Ward J, Clarkson J, Buckle P, Berman J, Lim R, Jun T. Prospective Hazard Analysis: Tailoring Prospective Methods To A Healthcare Context [Internet]. 2010. Available from: http://www.webcitation.org/6KZ0Y4R8E

9. Card AJ, Ward JR, Clarkson PJ. Beyond FMEA: The structured what-if technique (SWIFT). J Healthc Risk Manag. 2012;31(4):23-9.

10. Card AJ, Harrison H, Ward J, Clarkson PJ. Using prospective hazard analysis to assess an active shooter emergency operations plan. J Healthc Risk Manag. 2012;31(3):34-40.

11. Wreathall J, Nemeth C. Assessing risk: The role of probabilistic risk assessment (PRA) in patient safety improvement. Qual Saf Health Care. 2004;13(3):206-12.

12. Ekaette E, Lee RC, Cooke DL, Iftody S, Craighead P. Probabilistic Fault Tree Analysis of a Radiation Treatment System. Risk Anal. 2007;27(6):1395-410.

13. Woloshynowych M, Rogers S, Taylor-Adams S, Vincent C. The investigation and analysis of critical incidents and adverse events in healthcare. Heal Technol Assess. 2005;9(19):1-143, iii.

14. Card AJ, Ward JR, Clarkson PJ. Trust-Level Risk Evaluation and Risk Control Guidance in the NHS East of England. Risk Anal [Internet]. 2013 Dec 16 [cited 2013 Dec 17];0000. Available from: http://doi.wiley.com/10.1111/risa.12159

15. Amyotte P. An analysis of CSB investigation reports concerning the hierarchy of controls. Process Saf Prog [Internet]. 2011 [cited 2014 Jun 3];30(3):261-5. Available from: http://onlinelibrary.wiley.com/doi/10.1002/prs.10461/full

16. Behm M, Powell D. Problem Solving, Are Higher-Order Controls Ignored? Prof Saf. 2014;(February):34-40.

17. Engineering Professors Council. The EPC Engineering Graduate Output Standard: Interim Report of the EPC Output Standards Project. Godalming, UK; 2000. 
18. Bagian JP. Health care and patient safety: The failure of traditional approaches - How human factors and ergonomics can and MUST help. Hum Factors Ergon Manuf.

2012;22(1):1-6.

19. Pham JC, Kim GR, Natterman JP, Cover RM, Goeschel CA, Wu AW, Pronovost PJ. ReCASTing the RCA: an improved model for performing root cause analyses. Am J Med Qual. 2010 Jan;25(3):186-91.

20. Percarpio KB, Watts BV, Weeks WB. The effectiveness of root cause analysis: what does the literature tell us? Jt Comm J Qual Saf. 2008 Jul;34(7):391-8.

21. Landrigan CP, Parry GJ, Bones CB, Hackbarth AD, Goldmann DA, Sharek PJ. Temporal trends in rates of patient harm resulting from medical care. NEJM. 2010 Nov;363(22):2124-34.

22. Card AJ. The Active Risk Control (ARC) Toolkit: A New Approach to Designing Risk Control Interventions. J Healthc Risk Manag. 2014;33(4):5-14.

23. Card AJ, Ward JR, Clarkson PJ. Rebalancing Risk Management -Part 2: The Active Risk Control (ARC) Toolkit. J Healthc Risk Manag. In press.

24. Card AJ. A new tool for hazard analysis and force field analysis: The Lovebug Diagram. Clin Risk [Internet]. 2013;00(00):00. Available from: http://cri.sagepub.com/content/19/4$5 / 87$

25. Card AJ, Ward JR, Clarkson PJ. Generating Options for Active Risk Control (GO-ARC): Introducing a Novel Technique. J Healthc Qual [Internet]. 2013;00(00):[Epub ahead of print]. Available from: http://onlinelibrary.wiley.com/doi/10.1111/jhq.12017/abstract

26. Proche Jr. RA, editor. Training Manual for the Patient Safety Training Kit: Tools for Educating Your Staff. Oakbrook Terrace, IL: Joint Commission Resources; 2006.

27. Grout JR. Mistake-proofing the design of health care processes [Internet]. Rockville, MD: AHRQ; 2007. Available from: http://www.ahrq.gov/qual/mistakeproof/

28. Bates D, Maechler M, Bolker B. lme4: Linear mixed-effects models using Eigen and S4 [Internet]. 2012. Available from: http://r-forge.r-project.org/projects/lme4/

29. Hollnagel E, Braithwaite J, Wears RL, editors. Resilient Health Care. Ashgate Publishing; 2013.

30. Habraken $\mathrm{M}$, van der Schaaf T. If only....: failed, missed and absent error recovery opportunities in medication errors. Qual Saf Health Care. 2010 Feb;19(1):37-41.

31. Lyndon A. Skillful Anticipation: Maternity Nurses' Perspectives on Maintaining Safety. Qual Saf Healthc. 2010 Feb;19(5):e8. 
32. ISO. ISO 31000: Risk management - Principles and guidelines on implementation. Event (London). Geneva; 2009.

33. Serrat O. The five whys technique [Internet]. International Publications. Paper 198. Washington, DC; 2010 p. 1-3. Available from: http://digitalcommons.ilr.cornell.edu/intl/198/

34. Nicolini D, Waring J, Mengis J. The challenges of undertaking root cause analysis in health care: a qualitative study. J Health Serv Res Policy. 2011 Apr;16 Suppl 1(April):3441.

35. Greene W. Testing hypotheses about interaction terms in nonlinear models. Econ Lett. Elsevier B.V.; 2010;107(2):291-6.

36. Buis ML. Stata tip 87: Interpretation of interactions in nonlinear models. Stata J. 2010;10(2):305-8.

37. Ai C, Norton EC. Interaction terms in logit and probit models. Econ Lett. 2003;80:123-9.

38. Card AJ, Ward JR, Clarkson PJ. Rebalancing Risk Management -Part 1: The Process for Active Risk Control (PARC). J Healthc Risk Manag. In press.

39. Card AJ, Ward JR, Clarkson PJ. Getting to Zero: Evidence-based healthcare risk management is key. J Healthc Risk Manag. 2012;32(2):20-7.

40. Iedema R, Jorm C, Braithwaite J. Managing the scope and impact of root cause analysis recommendations. J Heal Organ Manag. 2008;22(6):569-85.

41. Mills PD, Neily J, Kinney LM, Bagian J, Weeks WB. Effective interventions and implementation strategies to reduce adverse drug events in the Veterans Affairs (VA) system. Qual Saf Health Care. 2008;17(1):37-46.

42. Mills PD, Neily J, Luan DD, Stalhandske E, Weeks WB. Using Aggregate Root Cause Analysis to Reduce Falls and Related Injuries. Jt Comm J Qual Patient Saf. Joint Commission Resources; 2005;31(1):21-31.

43. De Saint Maurice G, Auroy Y, Vincent C, Amalberti R. The natural lifespan of a safety policy: violations and system migration in anaesthesia. Qual Saf Healthc. 2010;19(4):32731.

44. Carthey J, Walker S, Deelchand V, Vincent C, Griffiths WH. Breaking the rules: understanding non-compliance with policies and guidelines. BMJ. 2011;343(d5283):1-5.

45. Vincent C. Science and Patient Safety. CMAJ. 2013;185(2):110-1. 
46. Shojania KG, Grimshaw JM. Evidence-based quality improvement: the state of the science. Health Aff. 2005;24(1):138-50.

47. Shekelle P, Pronovost P, et al. Advancing the Science of Patient Safety. Ann Intern Med. 2011;154(10):693-6.

48. Dul J, Bruder R, Buckle P, Carayon P, Falzon P, Marras WS, Wilson JR, van der Doelen B. A strategy for human factors/ergonomics: developing the discipline and profession. Ergonomics. 2012 Apr;55(4):377-95.

\section{ACKNOWLEDGEMENTS}

\section{Conflict of Interest Statement:}

The research was partly funded by the UK National Institute for Health Research (NIHR) Collaboration for Leadership in Applied Health Research and Care East of England (CLAHRC EoE) at Cambridge and Peterborough NHS Foundation Trust. The views expressed are those of the author(s) and not necessarily those of the NHS, the NIHR or the Department of Health. There is no financial conflict of interest, as the GO-ARC Technique has already been made available for free. The authors declare that they have no conflicts of interest related to this work.

\section{Informed Consent Statement:}

Ethical approval was sought and received from the University of Cambridge Department of Engineering. Informed consent was obtained from all participants. This work was not sponsored by any funding agency. The authors are solely responsible for the study design; the collection, analysis, or interpretation of data; the writing of the article; or the decision to submit it for publication. All researchers had access to the study data.

\section{You might also be interested in these papers on related topics \\ The GO-ARC Technique \\ Card AJ, Ward JR, Clarkson PJ. Generating Options for Active Risk Control (GO-ARC): Introducing a Novel Technique. J Healthc Qual 2013;00:[Epub ahead of print]. Available from: http://www.academia.edu/3377753/Generating_Options_for_Active_Risk_Control_GO- ARC_Introducing_a_Novel_Technique}




\section{The Active Risk Control (ARC) Toolkit and the Process for Active Risk Control (PARC)}

Card AJ. The Active Risk Control (ARC) Toolkit: A New Approach to Designing Risk Control Interventions. $J$ Healthc Risk Manag 2014;33:5-14. Available from: http://www.academia.edu/7094246/The_Active_Risk_Control_ARC_Toolkit_A_New_Approach_to_Designin g_Risk_Control_Interventions

Card AJ, Ward JR, Clarkson PJ. Rebalancing Risk Management -Part 1: The Process for Active Risk Control (PARC). $J$ Healthc Risk Manag; In press. Available from: http://www.academia.edu/7992857/Rebalancing_Risk_Management_Part_1_The_Process_for_Active_Risk_Control_PARC_

Card AJ. The Active Risk Control (ARC) Toolkit. Evidence-Based Health Solutions, LLC. Available from: www.activeriskcontrol.com/tools-and-templates

\section{Shortfalls in current risk control practice}

Card AJ, Ward J, Clarkson PJ. Successful risk assessment may not always lead to successful risk control: A systematic literature review of risk control after root cause analysis. J Healthc Risk Manag 2012;31:6-12. Available from: https://www.academia.edu/1081937/Successful_Risk_Assessment_May_Not_Always_Lead_To_Successful_ Risk_Control_A_Systematic_Literature_Review_of_Risk_Control_after_Root_Cause_Analysis

Card AJ, Ward JR, Clarkson PJ. Trust-Level Risk Evaluation and Risk Control Guidance in the NHS East of England. Risk Anal 2014;34:1471-81. Available from: http://onlinelibrary.wiley.com/doi/10.1111/risa.12159/abstract

\section{Evidence-Based Healthcare Risk Management}

Card AJ, Ward JR, Clarkson PJ. Getting to Zero: Evidence-based healthcare risk management is key. J Healthc Risk Manag 2012;32:20-7. Available from: http://www.academia.edu/1952946/Getting_to_Zero_Evidencebased_healthcare_risk_management_is_key

\section{Structured brainstorming techniques}

Card AJ, Ward JR, Clarkson PJ. Generating Options for Active Risk Control (GO-ARC): Introducing a Novel Technique. J Healthc Qual 2013;00:[Epub ahead of print]. Available from: http://www.academia.edu/3377753/Generating_Options_for_Active_Risk_Control_GOARC_Introducing_a_Novel_Technique

Card AJ, Ward JR, Clarkson PJ. Beyond FMEA: The structured what-if technique (SWIFT). J Healthc Risk Manag 2012;31:23-9. Available from: https://www.academia.edu/1269393/Beyond_FMEA_The_Structured_WhatIf_Technique_SWIFT_

Card AJ. A new tool for hazard analysis and force field analysis: The Lovebug Diagram. Clin Risk 2013;19:87-92. Available from: http://www.academia.edu/4650708/A_new_tool_for_hazard_analysis_and_force_field_analysis_The_Lovebu g_Diagram 